University of Nebraska - Lincoln

DigitalCommons@University of Nebraska - Lincoln

2013

\title{
Extremity cooling for heat stress mitigation in military and occupational settings
}

David W. DeGroot

U.S. Army Research Institute of Environmental Medicine, david.w.degroot.mil@mail.mil

Richard P. Gallimore

Battelle Memorial Institute

Shawn M. Thompson

Brooke Army Medical Center

Robert W. Kenefick

U.S. Army Research Institute of Environmental Medicine

Follow this and additional works at: https://digitalcommons.unl.edu/usarmyresearch

DeGroot, David W.; Gallimore, Richard P.; Thompson, Shawn M.; and Kenefick, Robert W., "Extremity cooling for heat stress mitigation in military and occupational settings" (2013). US Army Research. 193. https://digitalcommons.unl.edu/usarmyresearch/193

This Article is brought to you for free and open access by the U.S. Department of Defense at DigitalCommons@University of Nebraska - Lincoln. It has been accepted for inclusion in US Army Research by an authorized administrator of DigitalCommons@University of Nebraska - Lincoln. 
Review

\title{
Extremity cooling for heat stress mitigation in military and occupational settings
}

\author{
David W. DeGroot ${ }^{\mathrm{a}, *, 1}$, Richard P. Gallimore ${ }^{\mathrm{b}}$, Shawn M. Thompson ${ }^{\mathrm{c}}$, Robert W. Kenefick ${ }^{\mathrm{a}}$ \\ ${ }^{a}$ Thermal and Mountain Medicine Division, U.S. Army Research Institute of Environmental Medicine, Natick, MA 01760, United States \\ ${ }^{\mathrm{b}}$ Battelle Memorial Institute, Natick Operations supporting Natick Soldier Research, Development, and Engineering Center, Natick, MA 01760, United States \\ ${ }^{\mathrm{c}}$ Brooke Army Medical Center, Ft Sam Houston, TX 78219, United States
}

\section{A R T I C L E I N F O}

Article history:

Received 31 July 2012

Accepted 26 March 2013

Available online 3 April 2013

Keywords:

Core temperature

Exertional heat illness

Active cooling

Heat stress

Hyperthermia

\begin{abstract}
A B S T R A C T
Physical work, high ambient temperature and wearing protective clothing can elevate body temperature and cardiovascular strain sufficiently to degrade performance and induce heat-related illnesses. We have recently developed an Arm Immersion Cooling System (AICS) for use in military training environments and this paper will review literature supporting such an approach and provide details regarding its construction. Extremity cooling in cool or cold water can accelerate body (core temperature) cooling from 0.2 to $1.0{ }^{\circ} \mathrm{C} / 10 \mathrm{~min}$ vs. control conditions, depending on the size/surface area of the extremity immersed. Arm immersion up to the elbow results in greater heat loss than hand- or foot-only immersion and may reduce cardiovascular strain by lowering heart rate by $10-25$ beats/min and increase work tolerance time by up to $60 \%$. The findings from studies in this paper support the use of AICS prototypes, which have been incorporated as part of the heat stress mitigation procedures employed in US Army Ranger Training and may have great application for sports and occupational use. Published by Elsevier Ltd.
\end{abstract}

\section{Contents}

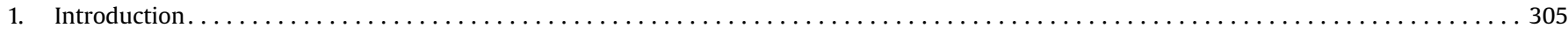

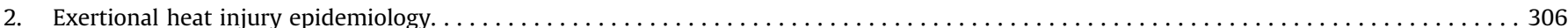

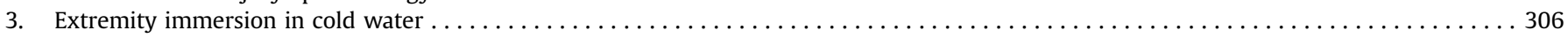

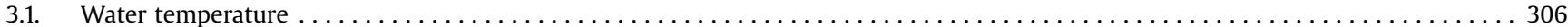

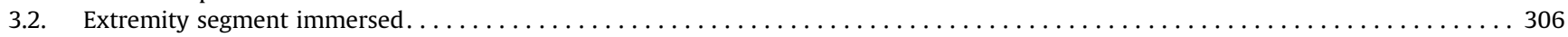

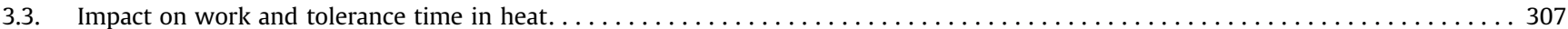

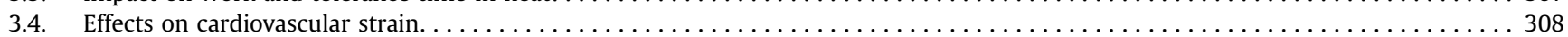

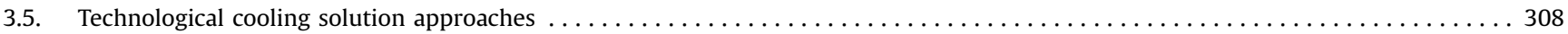

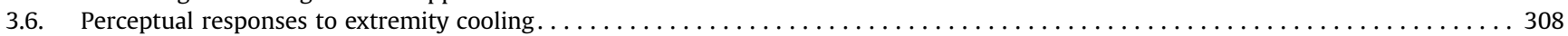

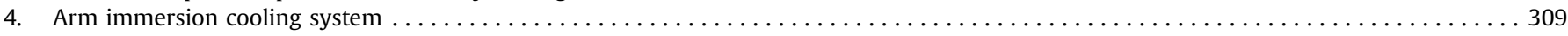

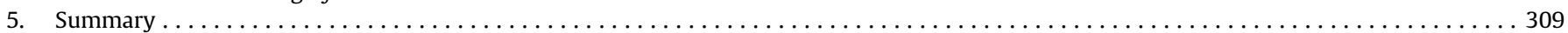

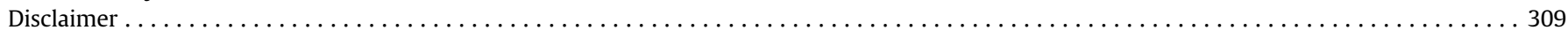

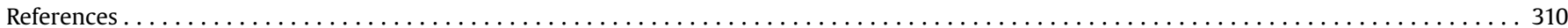

\section{Introduction}

Numerous commercial and industrial occupational settings, as well as military operational and training exercises, expose individuals to considerable heat stress due to high environmental heat and/or a high rate of metabolic heat production (Carter et al., 2005;

\footnotetext{
* Corresponding author. Tel.: +1 410417 2854; fax: +1 4104365449.

E-mail address: david.w.degroot.mil@mail.mil (D.W. DeGroot).

${ }^{1}$ Present Address: US Army Public Health Command, 5158 Blackhawk Rd, Aberdeen, MD 21010, United States.
}

Centers for Disease Control and Prevention, 2008). As a result body heat storage and associated cardiovascular strain limit exercise performance and increase the risk of exertional heat illness (EHI) (Carter et al., 2005; Sawka et al., 2012). In a number of occupational and military settings it may be biophysically difficult to dissipate body heat due to very hot ambient conditions and/or wearing needed protective clothing or equipment. Clothing/equipment limiting heat loss is common in numerous military, firefighting, hazmat incident, law enforcement, and sporting endeavors (e.g., American Football) (Cheuvront et al., 2003). When physiological cooling is insufficient, active cooling countermeasures may be capable of 
extending work performance time and reducing EHI incidence and severity (O'Hara et al., 2008).

The purpose of this paper is to review literature on extremity cooling and present a prototype Arm Immersion Cooling Systems (AICS) which we have developed and successfully implemented at military training sites. We will also present information demonstrating that extremity immersion cooling is highly effective and well received by users.

\section{Exertional heat injury epidemiology}

In the active duty military, there are typically over 300 cases of exertional heat stroke and over 2000 cases of other reportable heat illness hospitalizations in the training environment per year (Army Medical Surveillance Activity, 2012). In the civilian sector the incidence of $\mathrm{EHI}$ is more difficult to determine, as the diagnosis of heat stroke is not required to be reported in any US state (Howe and Boden, 2007). It has been reported, however, that exertional heat stroke is the third leading cause of death in athletes (Howe and Boden, 2007). The Centers for Disease Control and Prevention have reported that from 1992 to 2006 there were $\sim 30$ worker heatrelated deaths per year in the US (Centers for Disease Control and Prevention, 2008). Numerous organizations, including the US Army (Department of the Army, 2003), the American College of Sports Medicine (Armstrong et al., 2007), the National Athletic Trainers Association (Binkley et al., 2002), and various occupational and industrial safety groups have published heat injury prevention and treatment guidelines. However, as large-scale retrospective data demonstrate, EHI continues to be a problem (Carter et al., 2005) and additional mitigation procedures, such as extremity cooling in a field environment, are needed (O'Hara et al., 2008). Because of the characteristics of the affected individuals, EHI are viewed as preventable injuries. Active cooling via extremity immersion has been shown to lower heart rate and core temperature, and may be part of a risk management plan for heat stress mitigation. While immersion cooling may not prevent injury, it may help lessen EHI severity.

\section{Extremity immersion in cold water}

Extremity immersion can be an effective method for reducing core temperature and extending work for the following reasons: the heat transfer coefficient of water is approximately 25 times greater than air; the extremities have relatively large surface area to mass ratios compared to the torso; and blood flow through the cutaneous vasculature is very high when core temperature is elevated.. As a result of these characteristics, a number of investigators have examined the use of extremity immersion for the reduction of core temperature. Practical questions regarding implementation of extremity immersion include optimal water temperature, choice of anatomical site (hands vs hands+forearms vs feet vs feet+lower leg), and effects on subsequent work bouts, cardiovascular strain and perceptual benefits, each of which will be considered in the following sections.

\subsection{Water temperature}

Under normothermic conditions, cutaneous vasoconstriction is the "typical" response of a body segment to immersion in cool or cold water. This response occurs in order to limit the rate of heat transfer to the environment. However, the reflex control of skin blood flow in response to core temperature takes precedence over local control of skin blood flow (Johnson and Park, 1979; Wyss et al., 1974) and the cutaneous vasoconstrictor response to cold exposure, while present, can be attenuated when core temperature is elevated
(House et al., 2003). Several studies of extremity immersion have hypothesized that the elevated core temperature helps maintain cutaneous vasodilation despite the local effects of cool water and is partly responsible for the observed cooling rates (House, 1998; House et al., 1997; Livingstone et al., 1989, 1995).

Immersion in water temperatures ranging from 10 to $30{ }^{\circ} \mathrm{C}$ has been studied by a number of investigators (Allsopp and Poole, 1991; Giesbrecht et al., 2007; House, 1998; House et al., 1997; Livingstone et al., 1989). Each of these investigations reported that the cooler the water, or the greater the core-to-water temperature gradient, the greater the rate of cooling. For example, Livingstone and colleagues had participants immerse their hands in a water calorimeter (range: $10-30{ }^{\circ} \mathrm{C}$ ) and performed a regression analysis which indicated a linear relation between bath temperature and heat loss (Livingstone et al., 1989). House (House, 1998; House et al., 1997) heat stressed participants wearing firefighter protective clothing while performing stepping exercise in a $40{ }^{\circ} \mathrm{C}$ environment. Work continued until core temperature reached $38.5^{\circ} \mathrm{C}$. Following exercise cessation the participants immersed their hands in 10,20 , or $30^{\circ} \mathrm{C}$ water. While all three water temperatures were effective in reducing core temperature vs. a non-cooling control trial, 10 and $20{ }^{\circ} \mathrm{C}$ water were superior to $30{ }^{\circ} \mathrm{C}$ water. Core temperature declined $\sim 0.95{ }^{\circ} \mathrm{C}$ during the first $10 \mathrm{~min}$ of immersion in $10^{\circ} \mathrm{C}$ water and $0.75^{\circ} \mathrm{C}$ in $20^{\circ} \mathrm{C}$ water. These data also indicate that the cooling power provided by $20^{\circ} \mathrm{C}$ water $(318 \mathrm{~W})$ was nearly that of $10{ }^{\circ} \mathrm{C}$ water $(433 \mathrm{~W})$; while the cooling power of $30{ }^{\circ} \mathrm{C}$ water was only $134 \mathrm{~W}$. However, the literature is equivocal, as Giesbrecht and colleagues reported no difference in core temperature reduction between control, 10 and $20{ }^{\circ} \mathrm{C}$ water immersion trials (Giesbrecht et al., 2007). In this study participants underwent three exercise:cooling trials and while there were no differences in cooling rates between treatment groups, combined hand and forearm immersion in $10{ }^{\circ} \mathrm{C}$ water resulted in the lowest core temperature during the 3rd work: rest cycle, due to greater after drop. The reduction in core temperature was $\sim 0.4{ }^{\circ} \mathrm{C}$ per $10 \mathrm{~min}$ of immersion for all conditions, during the first work-rest cycle. By the start of the third work-rest cycle, core temperature was the lowest in participants who immersed their hands and forearms in $10{ }^{\circ} \mathrm{C}$ water, suggesting that the benefits of extremity immersion cooling may not be apparent unless multiple bouts of exercise are to be performed.

When ice and/or water supply and resupply in a field environment are taken into consideration, water as 'warm' as $20^{\circ} \mathrm{C}$ still provides significant cooling power (House, 1998; Livingstone et al., 1989; Selkirk et al., 2004); therefore it may not be necessary to maintain water temperature in the $10{ }^{\circ} \mathrm{C}$ range, which would have the benefit of extending the useful time of a given volume of cold water and reducing the logistical burden of keeping the water at $10{ }^{\circ} \mathrm{C}$. However, repeated use by multiple individuals and ambient environment conditions may increase water bath temperature such that immersion cooling is no longer beneficial, requiring periodic ice and/or water resupply.

It should be noted that each of the studies that investigated water bath temperatures used $10{ }^{\circ} \mathrm{C}$ or greater water. It is possible that water colder than $10{ }^{\circ} \mathrm{C}$ is not necessarily better, as the reflex inhibition of vasoconstriction due to elevated core temperature may be over-ridden, as suggested by Taylor and colleagues (2008). Further research concerning water bath temperature less than $10{ }^{\circ} \mathrm{C}$ is warranted (Fig. 1 ).

\subsection{Extremity segment immersed}

Consideration of the extremity segment immersed may be important and has been examined in the literature. In order to determine the effect of immersing only the hands, vs. the hands and the forearms, Giesbrecht (Giesbrecht et al., 2007), using similar 


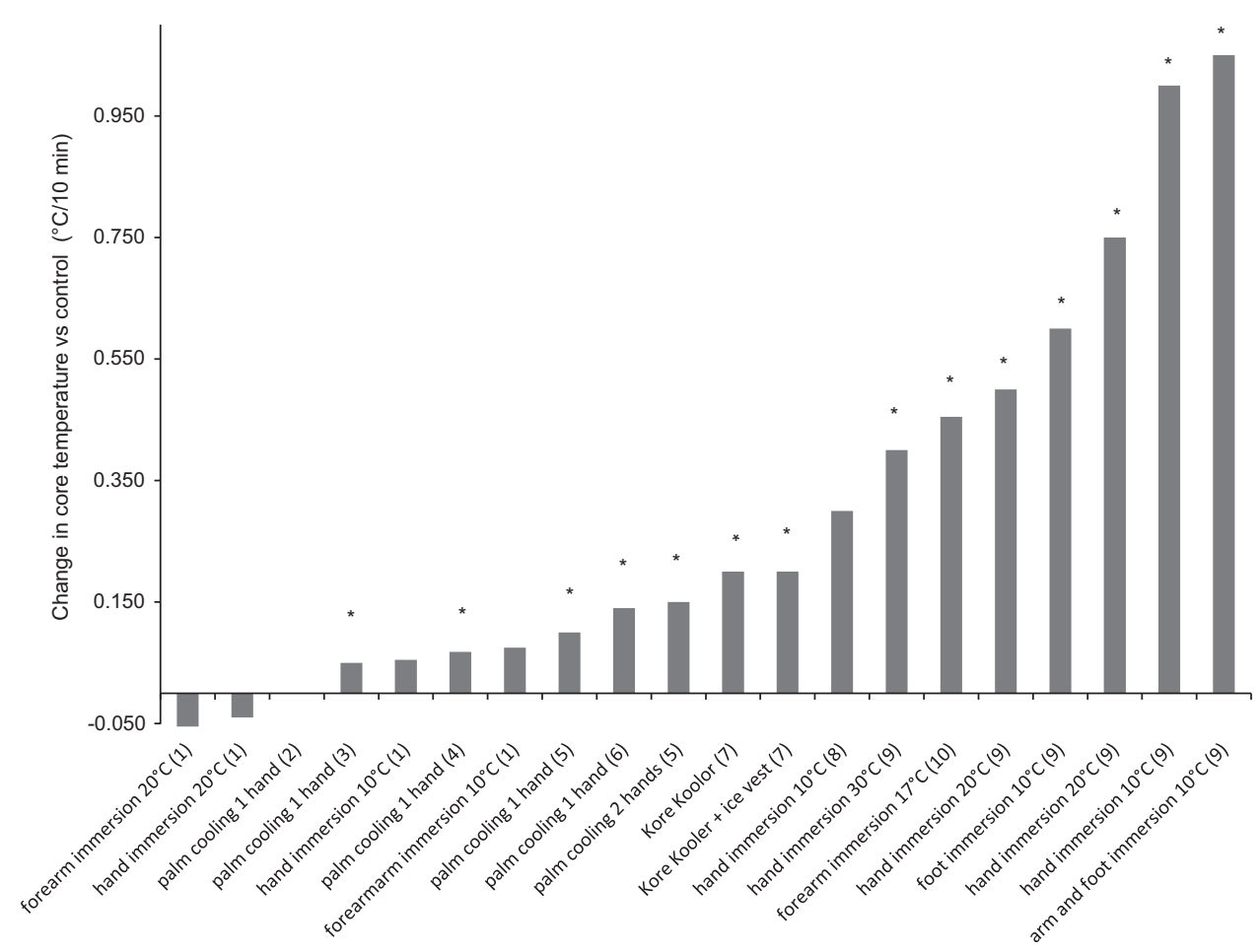

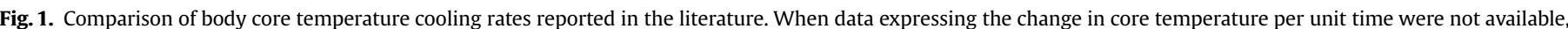

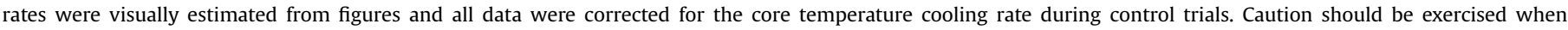

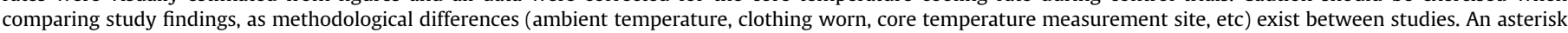

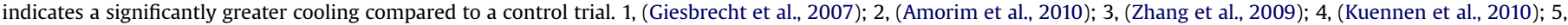
(Grahn et al., 2009); 6, (Grahn et al., 2005); 7, (Barr et al., 2011); 8, (Khomenok et al., 2008); 9, (House, 1998); 10, (House, 1998).

conditions to those employed by House (House, 1998; House et al., 1997), utilized heat flux transducers to quantify heat loss from different regions of the hands and arms. Participants immersed either their hands or hands and forearms (up to the elbow) in either 10 or $20^{\circ} \mathrm{C}$ water in addition to a non-cooling control. Heat loss from the hands was $\sim 175 \mathrm{~kJ}$ and $\sim 200 \mathrm{~kJ}$ during immersion in $20^{\circ}$ and $10{ }^{\circ} \mathrm{C}$ water, respectively, during the hands-only immersion trials. When the forearms were also immersed, heat loss increased from $\sim 75 \mathrm{~kJ}$ (not immersed) to $188 \pm 35 \mathrm{~kJ}\left(20^{\circ} \mathrm{C}\right)$ and $268 \mathrm{~kJ}\left(10^{\circ} \mathrm{C}\right)$. Heat loss from the upper arm, not immersed during any of the trials, was relatively constant at $58 \pm 5 \mathrm{~kJ}$.

In addition to hand or hand plus forearm immersion, foot immersion in cool water has also been studied. In addition to being impractical in a military training environment (Khomenok et al., 2008; Selkirk et al., 2004), data suggest that the rate of core temperature cooling during foot immersion is inferior compared to hand or hand and forearm immersion (House, 1998; Livingstone et al., 1995). Similar to hand or combined hand and forearm immersion, when immersing the feet, heat loss was greatest in the $10{ }^{\circ} \mathrm{C}$ water condition, such that heat loss was $\sim 3$ times greater at that temperature compared to $30{ }^{\circ} \mathrm{C}$ (Livingstone et al., 1995). Unfortunately core temperature was not reported in this study. House (1998) also studied foot immersion in $10^{\circ} \mathrm{C}$ water following exercise. The rate and magnitude of the decline in core temperature during this trial was significantly less than the hands or hands plus feet conditions, such that it took almost 20 min for core temperature to be reduced by $\sim 1.0{ }^{\circ} \mathrm{C}$. This rate was approximately twice as long as the cooling rate of that observed during hand and forearm immersion.

\subsection{Impact on work and tolerance time in heat}

Core cooling due to hand and forearm immersion in cool water can also have a beneficial effect during subsequent exposure, positively impacting work and tolerance time. Again using participants wearing firefighter protective clothing, Selkirk and colleagues had participants repeat a 50 min work: 30 min rest cycle until exhaustion or core temperature reached $39.6{ }^{\circ} \mathrm{C}$ (Selkirk et al., 2004). During the rest period the participants remained in the heat and either immersed their hands and forearms in $17{ }^{\circ} \mathrm{C}$ water or passively recovered (non-cooling control). The authors reported that reducing core temperature with hand and forearm immersion leads to improvements in total time in the heat and time spent working, by 66 and $62 \%$ respectively, compared to passive recovery. Tolerance time benefits of extremity immersion in $10{ }^{\circ} \mathrm{C}$ water were also reported by Khomenok and colleagues (2008). Participants immersed their hands and forearms in water for $10 \mathrm{~min}$ between two exercise bouts in the heat. All of the participants $(N=17)$ in the immersion trial completed the 125 min experimental protocol, while only 12 of the 17 participants did so in the passive recovery control trial. Participant attrition started at min 75 and mean tolerance time was $114 \mathrm{~min}$ in the control trial.

The literature on work performance time are equivocal, however the discrepancies may be due to methodological differences between studies. Amorim and colleagues included an extremity immersion trial in their study of a palm cooling device (Amorim et al., 2010). Participants, wearing an Army Combat Uniform, body armor and a rucksack, walked in $42{ }^{\circ} \mathrm{C}$ heat until core temperature reached $38.5^{\circ} \mathrm{C}$. They rested in the chamber for $41 \mathrm{~min}$ then repeated the exercise bout, again walking until core temperature reached $38.5{ }^{\circ} \mathrm{C}$. The cooling interventions were applied only during the rest period. Water bath temperature was manipulated to match the cooling plate temperature used during the palm cooling trials (either 15,18 , or $22^{\circ} \mathrm{C}$ ) and only one hand was immersed. The duration of the work periods was not significantly different between the water immersion and no-cooling control trials, in contrast to the findings of Selkirk and colleagues (2004). However, the thermal environment was more stressful (42 vs 
$35^{\circ} \mathrm{C}$ ) and the body segment immersed was smaller ( 1 hand vs. both hands and forearms) in the study by Amorim and colleagues (2010), likely contributing to the observed differences.

\subsection{Effects on cardiovascular strain}

The effects of extremity immersion on cardiovascular strain, unlike those on core temperature, are equivocal. While some investigations have reported that heart rate was $10-25 \mathrm{bpm}$ less than during non-cooling control (Khomenok et al., 2008; Selkirk et al., 2004) others have reported no difference in heart rate between conditions (Giesbrecht et al., 2007). Postural differences may explain the discrepancy, as subjects were seated or leaning over the cooling apparatus in the former studies (Khomenok et al., 2008; Selkirk et al., 2004) but remained standing in the latter (Giesbrecht et al., 2007). It should be noted, however, that heart rate differences persisted into subsequent work bouts in the aforementioned studies (Khomenok et al., 2008; Selkirk et al., 2004), suggesting that more than postural differences are involved. No previous studies have reported changes in skin blood flow or stroke volume changes during extremity immersion cooling; however using cold air exposure or water-perfused suit models, it is well-established that skin temperature and skin blood flow are directly related (DeGroot and Kenney, 2006; Stephens et al., 2001). Therefore, considering the reduction in heart rate reported in several studies, it is reasonable to speculate that skin blood flow requirements are reduced, peripheral pooling is reduced, and stroke volume is maintained.

Giesbrecht et al. also investigated sweat losses during immersion cooling. Over the course of three $20 \mathrm{~min}$ work/20 min rest cycles, sweat loss was $1458 \pm 270 \mathrm{~g}$ during the control condition vs. a mean of $1146 \pm 214 \mathrm{~g}$ for the four cooling conditions, a $22 \%$ reduction in sweat loss (Giesbrecht et al., 2007). This response was likely due to the established relationship between skin and core temperature as a driver of sweating response and the fact that core temperature was reduced by immersion (Nadel et al., 1971). However, the practical impact of this difference is debatable, as a $300 \mathrm{~mL}$ difference in sweat loss in a $75 \mathrm{~kg}$ individual, over a $2 \mathrm{~h}$ study period, corresponds to a body weight difference of only $0.4 \%$ and likely has minimal effect on reducing cardiovascular strain during exercise in the heat.

\subsection{Technological cooling solution approaches}

When considering possible solutions for providing extremity cooling in military and occupational settings, there are several commercially available portable cooling devices, such as the Kore Kooler $^{\mathrm{TM}}$ rehab chair and the Rapid Thermal Exchanger (RTX) device marketed by AVACore Technologies. The Kore Kooler provides a hand and forearm immersion solution by incorporating individual troughs for each limb into the structure of a portable chair. However, possibly due to the relatively small volume of water in the troughs, the cooling capacity of this device may not be as robust. In one study core temperature was reduced by just $0.2{ }^{\circ} \mathrm{C}$ in $15 \mathrm{~min}$ (Barr et al., 2011) compared to $0.4-1.0{ }^{\circ} \mathrm{C}$ in $10 \mathrm{~min}$ in other studies of hand and arm immersion as described previously (House, 1998; House et al., 1997; Selkirk et al., 2004). Additionally, the single-user design of the Kore Kooler may not be well-suited for larger groups of individuals, such as military training units consisting of dozens of soldiers who may benefit from an active cooling strategy in a short period of time. However for individuals or small groups the Kore Kooler may be a viable active cooling strategy.

Presently the RTX is no longer commercially available, however the concept of palm cooling accompanied by vacuum application to limit vasoconstriction while providing core cooling is novel and as such, should be reviewed. A $-40 \mathrm{mmHg}$ vacuum is maintained inside the housing that contains the cooling device that the user grasps with one hand. The vacuum is hypothesized to maintain blood flow through arteriovenous anastomoses in the hand and offset vasoconstriction due to skin contact with the metal cooling surface. The measured cooling power of the device is low, $\sim 30-$ $40 \mathrm{~W}$ compared to $\sim 200 \mathrm{~W}$ for forearm immersion in $10{ }^{\circ} \mathrm{C}$ water (Kuennen et al., 2010; Selkirk et al., 2004; Zhang et al., 2009), and subsequently the effectiveness of the device in reducing core temperature is minimal. Some studies have reported a cooling benefit of $\sim 0.30{ }^{\circ} \mathrm{C}$, compared to a non-cooling control, during 40-50 min of continuous use (Kuennen et al., 2010; Zhang et al., 2009) while others reported no benefit when the device was used only during recovery periods (Amorim et al., 2010). When used during aerobic exercise in a hot-dry environment, Grahn and colleagues reported that the rise in core temperature was attenuated by $\sim 0.7{ }^{\circ} \mathrm{C}$ vs non-cooling control (Grahn et al., 2005). When used by heavily insulated individuals who remain in a hot environment, simultaneous use of two palm cooling devices reduced core temperature by $1.3 \pm 0.2^{\circ} \mathrm{C}$ in $60 \mathrm{~min}$ vs $0.4 \pm 0.2{ }^{\circ} \mathrm{C}$ with no cooling (Grahn et al., 2009). The need for continuous use, during which one hand is completely unavailable, combined with low cooling power and effectiveness, may limit palm cooling with vacuum as a viable solution for providing active cooling to a heat-stressed individual.

\subsection{Perceptual responses to extremity cooling}

Several studies have examined the effects of extremity cooling on thermal comfort and/or thermal sensation as well as rating of perceived exertion (RPE) during subsequent exercise. Comfort and sensation are not interchangeable, as thermal comfort is the state of mind which expresses satisfaction with the thermal environment while thermal sensation describes how the environment feels to the individual (Gagge et al., 1967). Using a modified version of Gagge's thermal comfort scale, Selkirk and colleagues reported that hand and forearm immersion in $17^{\circ} \mathrm{C}$ water for 20 min significantly improved thermal comfort $(8.7 \pm 0.3$ during passive recovery vs $6.4 \pm 0.2$ during forearm immersion, where 7.0 was "comfortable"). Continuous use of a palm cooling device during recovery significantly improved thermal sensation ( $5.1 \pm 1.0$ vs. $6.4 \pm 1.2$ using Gagge's $1-10$ scale) but had no effect on thermal comfort (Kuennen et al., 2010). Use of the Kore Kooler rehab chair reduced thermal sensation from "hot" to "neutral", compared to "warm" during passive recovery. The lower thermal sensation was maintained during the subsequent exercise bout, which participants rated as "hot" vs. "very hot" during passive recovery (Barr et al., 2009; Barr et al., 2011).

The literature indicates that the Kore Kooler rehab chair does not have an effect on RPE during subsequent exercise (Barr et al., 2011 ) though there was a trend ( $p=0.06$, values not provided) for lower RPE when it was paired with an ice vest (Barr et al., 2009). Data are lacking concerning palm cooling or other extremity immersion cooling solutions possible effects on RPE during subsequent exercise.

The possibility of physical discomfort exists as a result of hand immersion in cold water, which may negatively impact an individual's use of such an intervention. Khomenok and colleagues asked participants to rate their hand discomfort using a 0-10 scale during immersion in $10{ }^{\circ} \mathrm{C}$ water (Khomenok et al., 2008). During hand immersion the discomfort ratings were $3.25 \pm 0.3$ and $4.0 \pm 0.4$ for the first and second recovery periods, which was not significantly different from the ratings during the nonimmersion recovery periods $(4.24 \pm 0.4$ and $4.68 \pm 0.6$, respectively). These data suggest that $10 \mathrm{~min}$ of hand immersion in $10{ }^{\circ} \mathrm{C}$ water does not cause undue physical discomfort. 


\section{Arm immersion cooling system}

Over the past several years, in an attempt to take advantage of the well-documented efficacy of extremity immersion for reducing core temperature, the US Army Research Institute of Environmental Medicine and the Natick Solider Research, Development and Engineering Command have been jointly developing an Arm Immersion Cooling System (AICS) for use by Soldiers in the training environment (Fig. 2). The goal was to develop a solution that was suitable for use by multiple soldiers at once, that was lightweight and easily transportable, and presented minimal logistical burden to unit cadre and staff. We initially developed a single AICS, which was supplied to the US Army Airborne School at Ft Benning, GA. Based on their feedback we constructed six each of two different 2nd generation variants, focusing on reducing weight and enhancing portability; these were also provided to Airborne School, as well as to Ranger Training Brigade at Ft Benning and to the Special Forces Assessment and Selection course at Camp Mackall, NC. Anecdotal evidence from some users has strongly suggested a reduction in the incidence of EHI and each training location indicated a desire to have more AICS made available for their use.

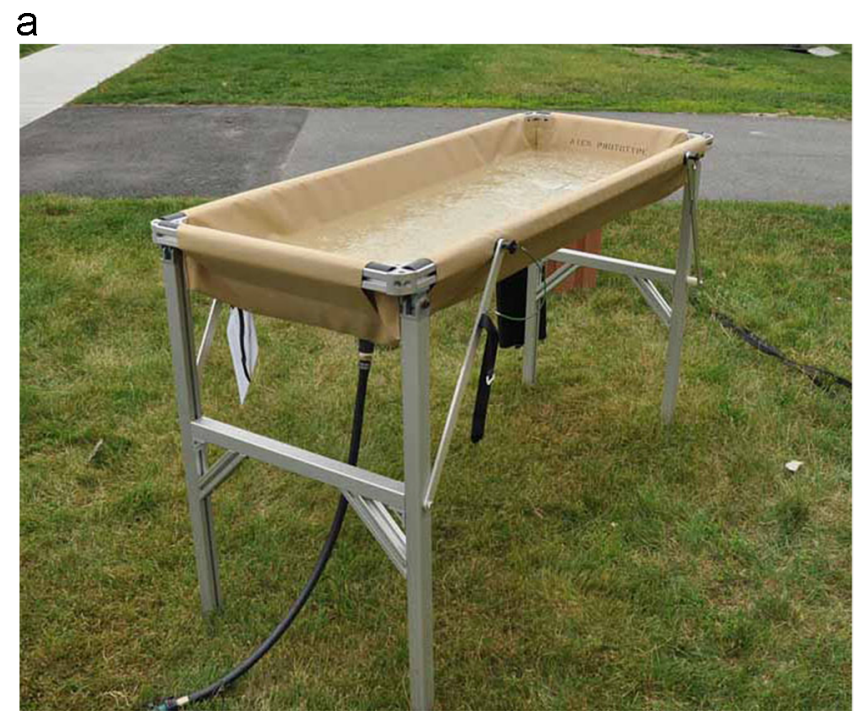

b

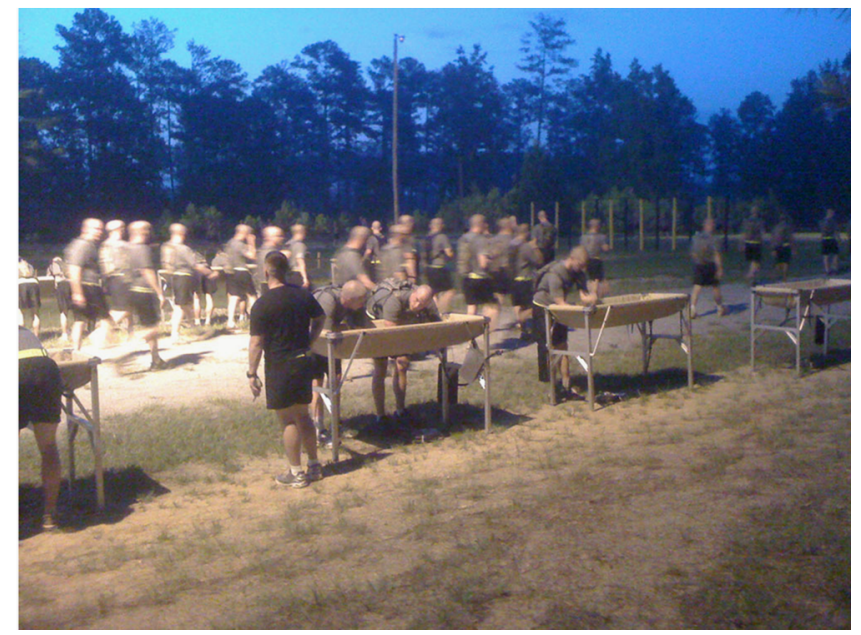

Fig. 2. Panel A. Prototype Arm Immersion Cooling System set up and ready for use. Panel B. Prototype Arm Immersion Cooling Systems in use at Ranger School, Ft Benning, GA. Unit leaders strategically place the AICS after high-intensity training events in order to facilitate cooling before moving on to the next event.
In cooperation and with the support of the Training and Doctrine Command Surgeons office, a 3rd generation AICS was developed, which featured further design refinements. The 3rd generation AICS weighs $<30 \mathrm{~kg}$ when empty, measures $1.5 \mathrm{~m}$ long $\times 0.6 \mathrm{~m}$ wide $\times 0.1 \mathrm{~m}$ deep when folded for transport, contains $\sim 20$ gallons of water when set up, and can accommodate up to six users (three on each side) at a time. Some users have added ice to the trough in order to reduce the water temperature and subsequent immersion time necessary to achieve a desired level of cooling. However as previously discussed, it may be important to avoid using water that is too cold, as reflex vasoconstriction may limit effectiveness of the AICS. In order to achieve the goals of light weight and ease of transport, the frame of the AICS is constructed of aluminum and the legs fold. The AICS is strong enough to support the weight of multiple users leaning on it or to support the body weight of an exertional heat stroke victim, making it suitable for emergency immersion cooling, and features an integrated headrest in order to maintain an open airway.

Supplied water temperature and ice quantity may vary in the field, leading to variable water trough temperatures. Additionally, the temperature will increase with repeated use by large numbers of individuals. In order to identify the appropriate immersion time, the AICS features an integrated thermometer and an immersion time table, which displays the estimated time necessary to achieve a $1.0{ }^{\circ} \mathrm{C}$ drop in core temperature, based on published data (House, 1998; House et al., 1997; Selkirk et al., 2004). Due to the variations in intensity between different military schools (basic training, Ranger School, Airborne School), unit cadre are instructed to identify events with a high risk of EHI and to implement the AICS accordingly. For example, in Ranger School cadre may elect to place AICS units only at the end of a long road march route, while in basic training, with generally less-fit individuals and lessrigorous standards, timed breaks for cooling during a road march may be implemented. Currently there are $\sim 100$ 3rd generation AICS in use at multiple training sites throughout the southern United States.

\section{Summary}

From research studies (Giesbrecht et al., 2007; House, 1998; House et al., 1997; Selkirk et al., 2004) it can be concluded that (1) hand or hand and forearm immersion in cool water is preferable to foot immersion due to greater rate of cooling and/or convenience factors regarding removing footwear; (2) $10^{\circ} \mathrm{C}$ and $20^{\circ} \mathrm{C}$ water provides greater cooling power than $30^{\circ} \mathrm{C}$ water; (3) $20^{\circ} \mathrm{C}$ water is still effective and allowing colder water to warm to $20^{\circ} \mathrm{C}$ through repeated use may reduce logistical demands; (4) work- and total tolerance time may be improved. In addition, a prototype AICS system has been described that may have broad application for sports and occupational use. Whether AICS use translates to reduced incidence and/or severity of exertional heat injury is unknown and is currently under investigation.

\section{Disclaimer}

This study is approved for public release, distribution is unlimited. The opinions or assertions contained herein are the private views of the authors and are not to be construed as official or reflecting the views of the U.S. Army or the Department of Defense. Any citations of commercial organizations and trade names in this report do not constitute an official U.S. Department of the Army endorsement of approval of the products or services of these organizations. 


\section{References}

Allsopp, A.J., Poole, K.A., 1991. The effect of hand immersion on body temperature when wearing impermeable clothing. J. Roy. Nav. Med. Serv. 77, 41-47.

Amorim, F.T., Yamada, P.M., Robergs, R.A., Schneider, S.M., 2010. Palm cooling does not reduce heat strain during exercise in a hot, dry environment. Appl. Physiol. Nutr. Metab. 35, 480-489.

Armstrong, L.E., Casa, D.J., Millard-Stafford, M., Moran, D.S., Pyne, S.W., Roberts, W. O., 2007. American College of Sports Medicine position stand. Exertional heat illness during training and competition. Med. Sci. Sports Exercise 39, 556-572.

Army Medical Surveillance Activity, 2012. Update: heat injuries, active component, U.S. Armed Forces, 2011. Medical Surveillance Monthly Report 19, 14-16.

Barr, D., Gregson, W., Sutton, L., Reilly, T., 2009. A practical cooling strategy for reducing the physiological strain associated with firefighting activity in the heat. Ergonomics 52, 413-420.

Barr, D., Reilly, T., Gregson, W., 2011. The impact of different cooling modalities on the physiological responses in firefighters during strenuous work performed in high environmental temperatures. Eur. J. Appl. Physiol. 111, 959-967.

Binkley, H.M., Beckett, J., Casa, D.J., Kleiner, D.M., Plummer, P.E., 2002. National Athletic Trainers' Association position statement: exertional heat illnesses. J. Athl. Train. 37, 329-343.

Carter III, R., Cheuvront, S.N., Williams, J.O., Kolka, M.A., Stephenson, L.A., Sawka, M. N., Amoroso, P.J., 2005. Epidemiology of hospitalizations and deaths from heat illness in soldiers. Med. Sci. Sports Exercise 37, 1338-1344.

Centers for Disease Control and Prevention, 2008. Heat-related deaths among crop workers- United States, 1992-2006. Morbidity and Mortality Weekly Report 57, 649-653.

Cheuvront, S.N., Kolka, M.A., Cadarette, B.S., Montain, S.J., Sawka, M.N., 2003. Efficacy of intermittent, regional microclimate cooling. J. Appl. Physiol. 94, 1841-1848.

DeGroot, D.W., Kenney, W.L., 2006. Impaired defense of core temperature in aged humans during mild cold stress. AJP - Regul. Integrative Comp. Physiol. 292, R103-R108.

Department of the Army, 2003. Heat stress control and heat casualty management TB MED 507. Headquarters, Department of the Army and Air Force.

Gagge, A.P., Stolwijk, J.A., Hardy, J.D., 1967. Comfort and thermal sensations and associated physiological responses at various ambient temperatures. Environ. Res. 1, 1-20.

Giesbrecht, G.G., Jamieson, C., Cahill, F., 2007. Cooling hyperthermic firefighters by immersing forearms and hands in 10 degrees $C$ and 20 degrees $C$ water. Aviat. Space Environ. Med. 78, 561-567.

Grahn, D.A., Cao, V.H., Heller, H.C., 2005. Heat extraction through the palm of one hand improves aerobic exercise endurance in a hot environment. J. Appl. Physiol. 99, 972-978.

Grahn, D.A., Dillon, J.L., Heller, H.C., 2009. Heat loss through the glabrous skin surfaces of heavily insulated, heat-stressed individuals. J. Biomech. Eng. 131, 071005 .
House, J., 1998. Extremity cooling as a method for reducing heat strain. J. Def. Sci. 3, $108-114$

House, J.R., Holmes, C., Allsopp, A.J., 1997. Prevention of heat strain by immersing the hands and forearms in water. J. R. Nav. Med. Serv. 83, 26-30.

House, J.R., Lunt, H., Magness, A., Lyons, J., 2003. Testing the effectiveness of techniques for reducing heat strain in Royal Navy nuclear, biological and chemical cleansing stations' teams. J. R. Nav. Med. Serv. 89, 27-34.

Howe, A.S., Boden, B.P., 2007. Heat-related illness in athletes. Am. J. Sports Med. 35 1384-1395.

Johnson, J.M., Park, M.K., 1979. Reflex control of skin blood flow by skin temperature: role of core temperature. J. Appl. Physiol. 47, 1188-1193.

Khomenok, G.A., Hadid, A., Preiss-Bloom, O., Yanovich, R., Erlich, T., Ron-Tal, O., Peled, A., Epstein, Y., Moran, D.S., 2008. Hand immersion in cold water alleviating physiological strain and increasing tolerance to uncompensable heat stress. Eur. J. Appl. Physiol. 104, 303-309.

Kuennen, M.R., Gillum, T.L., Amorim, F.T., Kwon, Y.S., Schneider, S.M., 2010. Palm cooling to reduce heat strain in subjects during simulated armoured vehicle transport. Eur. J. Appl. Physiol. 108, 1217-1223.

Livingstone, S.D., Nolan, R.W., Cattroll, S.W., 1989. Heat loss caused by immersing the hands in water. Aviat. Space Environ. Med. 60, 1166-1171.

Livingstone, S.D., Nolan, R.W., Keefe, A.A., 1995. Heat loss caused by cooling the feet. Aviat. Space Environ. Med. 66, 232-237.

Nadel, E.R., Bullard, R.W., Stolwijk, J.A., 1971. Importance of skin temperature in the regulation of sweating. J. Appl. Physiol. 31, 80-87.

O'Hara, R., Eveland, E., Fortuna, S., Reilly, P., Pohlman, R., 2008. Current and future cooling technologies used in preventing heat illness and improving work capacity for battlefield soldiers: review of the literature. Mil. Med. 173, 653-657.

Sawka, M.N., Cheuvront, S.N., Kenefick, R.W., 2012. High skin temperature and hypohydration impair aerobic performance. Exp. Physiol. 97, 327-332.

Selkirk, G.A., McLellan, T.M., Wong, J., 2004. Active versus passive cooling during work in warm environments while wearing firefighting protective clothing. J. Occup. Environ. Hyg. 1, 521-531.

Stephens, D.P., Aoki, K., Kosiba, W.A., Johnson, J.M., 2001. Nonnoradrenergic mechanism of reflex cutaneous vasoconstriction in men. AJP - Heart Cir Physiol. 280, H1496-H1504.

Taylor, N.A., Caldwell, J.N., Van Den Heuvel, A.M., Patterson, M.J., 2008. To cool, but not too cool: that is the question-immersion cooling for hyperthermia. Med. Sci. Sports Exercise 40, 1962-1969. http://dx.doi.org/10.1249/MSS.0b013e31817eee9d.

Wyss, C.R., Brengelmann, G.L., Johnson, J.M., Rowell, L.B., Niederberger, M., 1974. Control of skin blood flow, sweating, and heart rate: role of skin vs. core temperature. J. Appl. Physiol. 36, 726-733.

Zhang, Y., Bishop, P.A., Casaru, C., Davis, J.K., 2009. A new hand-cooling device to enhance firefighter heat strain recovery. J. Occup. Environ. Hyg. 6, 283-288. 